\title{
Dose Dependent Prophylactic Efficacy of 6-Chlorotacrine in Soman-Poisoned Mice
}

\author{
Jiří Kassa*, Jan Korábečný
}

\begin{abstract}
Aim: The influence of the dose on the ability of promising newly prepared reversible inhibitor of acetylcholinesterase (6-chlorotacrine) to increase the resistance of mice against soman and the efficacy of antidotal treatment of soman-poisoned mice was evaluated. Methods: The evaluation of the effect of pharmacological pretreatment is based on the identification of changes of soman-induced toxicity that was evaluated by the assessment of its $\mathrm{LD}_{50}$ value and its $95 \%$ confidence limit using probit-logarithmical analysis of death occurring within 24 hrs after administration of soman. Results: The dose of 6-chlorotacrine significantly influences the prophylactic efficacy of 6 -chlorotacrine. Its highest dose was only able to significantly protect mice against acute toxicity of soman and increase the efficacy of antidotal treatment (atropine in combination with the oxime $\mathrm{HI}$-6) of soman-poisoned mice. In addition, the highest dose of 6-chlorotacrine was significantly more effective to protect mice from soman poisoning than its lowest dose. Conclusion: These findings demonstrate the important influence of the dose of 6-chlorotacine on its prophylactic efficacy in the case of pharmacological pretreatment of soman poisoning in mice.
\end{abstract}

\section{KEYWORDS}

soman; 6-chlorotacrine; atropine; HI-6; pharmacological pretreatment; mice

\section{AUTHOR AFFILIATIONS}

Department of Toxicology and Military Pharmacy, Faculty of Military Health Sciences, Hradec Králové, Czech Republic

* Třebešská 1575, Faculty of Military Health Sciences, 50001 Hradec Králové, Czech Republic; e-mail: kassa@pmfhk.cz

Received: 10 November 2017

Accepted: 27 January 2018

Published online: 23 April 2018

Acta Medica (Hradec Králové) 2017; 60(4): 140-145

https://doi.org/10.14712/18059694.2018.9

(c) 2017 The Authors. This is an open-access article distributed under the terms of the Creative Commons Attribution License (http://creativecommons.org/licenses/by/4.0), which permits unrestricted use, distribution, and reproduction in any medium, provided the original author and source are credited. 


\section{INTRODUCTION}

The highly toxic organophosphorus compounds, called nerve agents, are still considered to be the most dangerous chemical warfare agents. They exert their toxic effects mainly by inhibiting acetylcholinesterase (AChE, EC 3.1.1.7), the enzyme responsible for deactivating the neurotransmitter acetylcholine (ACh) at cholinergic synapses. Nerve agent-induced irreversible inhibition of AChE in the central as well as peripheral nervous system leads to accumulation of ACh in the central and peripheral cholinergic synapses and to subsequent stimulation of both central and peripheral muscarinic and nicotinic cholinergic receptors. Death occurs due to an acute cholinergic crisis, with signs and symptoms such as excessive salivation, lacrimation, urination, defecation, sweating, bronchoconstriction, neuromuscular block, generalized seizures, respiratory distress and respiratory failure (1-2).

The medical countermeasures of poisoning with organophosphorus compounds are usually based on a combined administration of a muscarinic cholinergic receptor antagonist to block the overstimulation of cholinergic receptors by accumulated ACh at muscarinic receptor sites and an oxime to reactivate nerve agent-inhibited AChE. Generally, anticholinergics (mainly atropine) are used for relieving muscarinic signs and symptoms whereas AChE reactivators (generally nucleophilic compounds with high affinity for phosphorus), called oximes, are used to repair the biochemical lesion by dephosphonylation of AChE and restoring its activity. Although the antidotes against nerve agents and organophosphorus insecticides have been developed based on the knowledge of above-mentioned basic mechanism of acute toxicity of organophosphorus compounds, their efficacy is limited (3-4).

One of the most resistant nerve agents is soman (pinacolyl methylfluorophosphonate). Its deleterious effects are extraordinarily difficult to counteract due to the very rapid dealkylation of the complex soman-AChE, called aging. The dealkylation of soman bound on the active site of AChE makes the nucleophilic attack of oximes almost impossible $(1,5)$. In addition, the main action of soman is in the central nervous system where the reactivating efficacy of all oximes is low owing to their limited penetration through blood-brain barrier (6-7). The unsatisfactory efficacy of antidotal treatment available for acute nerve agent poisonings, especially in the case of soman and tabun exposure, has brought another approach how to protect the humans from nerve agent-induced acute lethal toxic effects - using pharmacological pretreatment in the case of the threat of exposure to nerve agents. The term "pharmacological pretreatment" generally represents the medical countermeasures applied relatively shortly before penetration of a toxic agent into the organism with the aim of protecting the organism against its acute toxicity and increasing the effects of post-exposure antidotal treatment (8-10).

Up to date, the most common principle of pharmacological pretreatment is the protection of AChE against nerve agent-induced irreversible inhibition that is focused on the use of reversible cholinesterase inhibitors. Among reversible inhibitors of $\mathrm{AChE}$, the carbamate pyridostigmine bromide is generally accepted and commonly used for the pharmacological pretreatment of nerve agent poisonings. It is stockpiled by various armed forces for pretreatment purpose against nerve agent poisoning and has been used by several thousand servicemen during UN operation against Iraq in 1991 (11). However, pyridostigmine is only able to protect peripheral AChE from irreversible nerve agent-induced AChE phosphonylation, while nerve agents, especially fluorophosphonates, can cross the blood-brain barrier (BBB) and, thus, express their deleterious effects through their central toxic effects including centrally mediated seizure activity that can rapidly progress to status epilepticus and finally contribute to brain damage (12). Therefore, the shortage of effectiveness of pyridostigmine bromide alone to increase the resistance of nerve agent-exposed experimental animals was demonstrated (13).

Thus, the replacement of pyridostigmine bromide with sufficiently effective reversible inhibitors of AChE with low toxicity and ability to cross BBB has been an important goal for the pharmacological pretreatment of nerve agent poisonings because the small decrease of the brain AChE activity (up to 20\%) was found to be beneficial for an increase in the efficacy of pharmacological pretreatment and it does not affect the behavioral and neurophysiological functions of experimental animals according to our neurobehavioral research (14). A few years ago, a novel reversible inhibitor of AChE - 6-chlorotacrine (6-chloro1,2,3,4-tetrahydroacridine-9-amine hydrochloride) (Figure 1) was synthesized at our Department of Toxicology and Military Pharmacy to improve the efficacy of pharmacological pretreatment against nerve agents and potentially for the treatment of Alzheimer's disease. Recently, a promising ability of 6-chlorotacrine to increase the resistance of soman-poisoned mice and the efficacy of post-exposure antidotal treatment (atropine in combination with the oxime HI-6) of soman-poisoned mice was found (15). However, the dose of 6-chlorotacrine used in this study was too small to reach optimal inhibition of the brain AChE.

In the present study, the influence of the doses of 6-chlorotacrine on its prophylactic effect in the case of soman poisoning was studied.

\section{MATERIALS AND METHODS}

\section{ANIMALS}

Male NMRI mice weighing 20-25g were purchased from VELAZ (Prague, Czech Republic). They were kept in an air-conditioned room $\left(22 \pm 2{ }^{\circ} \mathrm{C}\right.$ and $50 \pm 10 \%$ relative humidity, with lights from 7.00 hrs a.m. to 7.00 hrs p.m.) and allowed access to standard food and tap water ad libitum. The mice were divided into groups of eight animals $(\mathrm{N}=8)$. Handling of experimental animals was done under the supervision of the Ethics Committee of the Faculty of Military Health Sciences in Hradec Králové (Czech Republic).

\section{CHEMICALS}

Soman was obtained from the Military Technical Institute in Brno (Czech Republic) and was $96.0 \%$ pure. Its purity 
was assayed by acidimetric titration. The purity of the oxime HI-6 and 6-chlorotacrine (Figure 1) was higher than $98 \%$. They were synthesized at the Department of Toxicology and Military Pharmacy of the Faculty of Military Health Sciences in Hradec Králové (Czech Republic). The purity of the oxime HI-6 and 6-chlorotacrine was analysed using HPLC. All other drugs and chemicals of analytical grade were obtained commercially and used without further purification. All substances were administered intramuscularly (i.m.) at a volume of $10 \mathrm{~mL} / \mathrm{kg}$ body weight (b.w.).

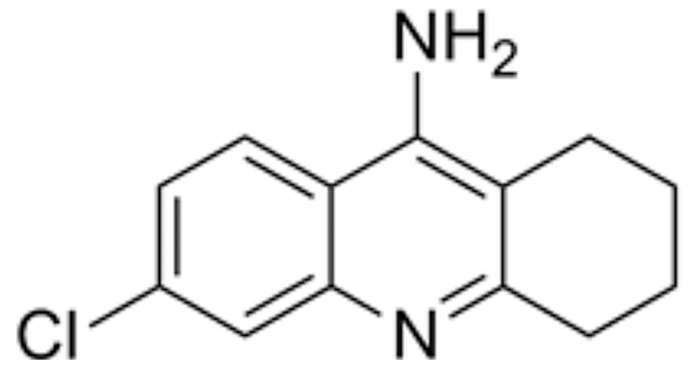

. $\mathrm{HCl}$

Fig. 1 Chemical structure of 6 -chlorotacrine.

\section{EVALUATION OF PROPHYLACTIC EFFICACY OF 6-CHLOROTACRINE}

To evaluate prophylactic efficacy of tested doses of 6-chlorotacrine, it was administered i.m. at three doses corresponding to 5,10 and $20 \%$ of its $\mathrm{LD}_{50}$ values 30 minutes before i.m. soman challenge. The $\mathrm{LD}_{50}$ value of 6-chlorotacrine $(10.08 \mathrm{mg} / \mathrm{kg})$ was assessed using probit-logarithmical analysis of death occurring within 24 hours after i.m. administration of 6-chlorotacrine at five doses with eight mice per dose (16) and published in our previous paper (15). The doses of tested reversible inhibitor of AChE were chosen to be sufficiently safe to avoid the potential adverse drug reactions in the peripheral as well as central compartment. Soman-induced toxicity was evaluated by the assessment of its $\mathrm{LD}_{50}$ value and its $95 \%$ confidence limit using probit-logarithmical analysis of death occurring within $24 \mathrm{hrs}$ after administration of soman at five different doses with eight animals per dose (16). The efficacy of tested doses of 6-chlorotacrine was expressed as protective ratio $\left(\mathrm{LD}_{50}\right.$ value of soman in pretreated mice / $\mathrm{LD}_{50}$ value of soman in non-pretreated mice).

\section{EVALUATION OF THE INFLUENCE OF 6-CHLOROTACRINE ON THE THERAPEUTIC EFFICACY OF ANTIDOTAL TREATMENT}

To evaluate the influence of 6-chlorotacrine on the therapeutic efficacy of antidotal treatment, the oxime HI- 6 at a dose corresponding to $5 \%$ of its $\mathrm{LD}_{50}$ in combination with atropine at a dose corresponding to $10 \mathrm{mg} / \mathrm{kg}$ was administered i.m. $1 \mathrm{~min}$ after soman administration. In addition, 6-chlorotacrine was administered i.m. at three doses corresponding to 5,10 and $20 \%$ of its $\mathrm{LD}_{50}$ value 30 minutes before i.m. soman challenge. Soman-induced toxicity was evaluated by the assessment of $\mathrm{LD}_{50}$ value and its $95 \%$ confidence limit using probit-logarithmical analysis of death occurring within $24 \mathrm{hrs}$ after administration of soman at five different doses with eight animals per dose (16). The influence of tested doses of 6-chlorotacrine on the therapeutic efficacy of antidotal treatment of soman poisoning was expressed as protective ratio $A\left(\mathrm{LD}_{50}\right.$ value of soman in pretreated mice with antidotal treatment/ $\mathrm{LD}_{50}$ value of soman in non-pretreated mice without antidotal treatment) and protective ratio $\mathrm{B}\left(\mathrm{LD}_{50}\right.$ value of soman in pretreated mice with antidotal treatment/ $\mathrm{LD}_{50}$ value of soman in non-pretreated mice with antidotal treatment). The differences between $\mathrm{LD}_{50}$ values were considered to be significant when $\mathrm{p}<0.05(16)$.

\section{RESULTS}

A comparison of the prophylactic efficacy of three doses of the reversible $\mathrm{AChE}$ inhibitor 6-chlorotacrine is presented in Table 1. All tested doses of 6-chlorotacrine were able to increase the resistance of experimental animals against acute toxicity of soman. However, there were marked differences in the prophylactic efficacy of 6-chlorotacrine depending on its dose used. Only the highest dose corresponding to $20 \%$ of its $\mathrm{LD}_{50}$ value was able to significantly increase the resistance of experimental animals against acute toxicity of soman $(p<0.05)$. Due to the prophylactic administration of 6-chlorotacrine at the highest dose, the $\mathrm{LD}_{50}$ value of soman was increased from $56.3 \mu \mathrm{g} / \mathrm{kg}$ to $110.5 \mu \mathrm{g} / \mathrm{kg}$. When soman at the dose corresponding to its $\mathrm{LD}_{50}$ value for unprotected animals was administered to animals prophylactically protected by 6 -chlorotacrine at a dose corresponding to $20 \%$ of its $\mathrm{LD}_{50}$ value, all animals survived within 24 hours.

A comparison of the benefit of all doses of reversible AChE inhibitor 6-chlorotacrine for the therapeutic efficacy of antidotal treatment of soman poisoning is presented in Table 2. All doses of 6-chlorotacrine markedly increased the efficacy of the antidotal treatment of soman-poisoned mice consisting of the oxime HI- 6 and atropine. Nevertheless, only the medium and the highest dose of 6-chlorotacrine were able to significantly increase the efficacy of antidotal treatment of soman poisoning $(p<0.05)$. Due to the prophylactic administration of 6-chlorotacrine at the doses corresponding to $10 \%$ and $20 \%$ of its $\mathrm{LD}_{50}$ value, the protective ratio induced by antidotal treatment of soman poisoning was increased from 2.10 to 3.81 or 4.11, resp. On the other hand, the prophylactic administration of the lowest dose of 6-chlorotacrine did not significanly influence the therapeutic efficacy of chosen antidotal treatment of soman-poisoned mice.

Tab. 1 Prophylactic effect of 6-chlorotacrine administered at three different doses on the $\mathrm{LD}_{50}$ value of soman in mice. Statistical significance: ${ }^{*} p<0.05$ (between non-pretreated mice and pretreated mice).

\begin{tabular}{|l|l|l|}
\hline Pretreatment & $\mathrm{LD}_{50}(\mu \mathrm{g} / \mathrm{kg}) \pm \mathbf{9 5 \%} \mathrm{CL}$ & $\begin{array}{l}\text { Protective } \\
\text { ratio }\end{array}$ \\
\hline- & $56.3(34.3-79.6)$ & - \\
\hline 6-chlorotacrine - 5\% LD $\mathrm{LD}_{50}$ & $68.1(59.2-74.6)$ & 1.21 \\
\hline 6-chlorotacrine - 10\% LD & $80.6(62.9-102.6)$ & 1.43 \\
\hline 6-chlorotacrine - 20\% LD & $\mathbf{1 1 0 . 5 ( 8 5 . 4 - 1 4 2 . 5 ) *}$ & $\mathbf{1 . 9 6}$ \\
\hline
\end{tabular}


Tab. 2 The influence of 6-chlorotacrine administered at three different doses on the ability of antidotal treatment to increase the $\mathrm{LD}_{50}$ value of soman in mice. Statistical significance: ${ }^{*} p<0.05$ (between non-pretreated and non-treated mice and pretreated and/or treated mice), ${ }^{x} p<0.05$ (between non-pretreated and treated mice and pretreated and treated mice).

\begin{tabular}{|l|l|l|l|l|}
\hline Pretreatment & Treatment & $\mathrm{LD}_{50}(\mu \mathrm{g} / \mathrm{kg}) \pm 95 \% \mathrm{CL}$ & Protective ratio A & Protective ratio B \\
\hline- & - & $87.0(70.2-107.8)$ & - & - \\
\hline- & $\begin{array}{l}\mathrm{HI}-6 \\
\text { atropine }\end{array}$ & $182.9(150.8-221.7)^{*}$ & 2.10 & 1.31 \\
\hline 6-chlorotacrine - 5\% LD 50 & $\begin{array}{l}\text { HI-6 } \\
\text { atropine }\end{array}$ & $239.6(163.0-313.7)^{*}$ & 2.75 & 1.81 \\
\hline 6-chlorotacrine - 10\% LD & $\begin{array}{l}\text { HI-6 } \\
\text { atropine }\end{array}$ & $\mathbf{3 3 1 . 3 ( 2 7 8 . 6 - 3 9 3 . 9 ) ^ { * , x }}$ & 3.81 & 1.95 \\
\hline 6-chlorotacrine - 20\% LD & $\begin{array}{l}\text { HI-6 } \\
\text { atropine }\end{array}$ & $\mathbf{3 5 7 . 5 ( 2 9 7 . 9 - 4 3 3 . 2 ) ^ { * , x }}$ & $\mathbf{4 . 1 1}$ & \\
\hline
\end{tabular}

\section{DISCUSSION}

The effective pharmacological pretreatment seems to be very important in the case of soman exposure because soman-induced deleterious effects are very difficult to counteract due to low reactivating efficacy of currently used oximes (17). The reason for the weak reactivating potency of the oximes is very rapid aging of phosphonylated AChE (18-19).

It is generally known that the therapeutic efficacy of antidotal treatment of nerve agent poisoning can be increased when it is combined with the pharmacological pretreatment by reversible AChE inhibitors $(8,20)$. The protection of AChE against irreversible inhibition focused on the use of reversible AChE inhibitors (mostly carbamates) is the most common principle of pharmacological pretreatment of nerve agent poisonings. They are able to inhibit AChE reversibly with spontaneous recovery of its activity. Recovered activity of AChE serves as a source of the active enzyme (8). Protection of AChE against inhibition - i.e. remaining intact $\mathrm{AChE}$ is a basic requirement for normal function of peripheral and central cholinergic nervous systems. Due to this pharmacological pretreatment, the enzyme AChE became resistant to nerve agent-induced irreversible inhibition (21).

The reversible cholinesterase inhibitor pyridostigmine bromide, that transiently carbamylates the active site of $\mathrm{AChE}$ to prevent any phosphonylation, has been used for more than 50 years in the palliative treatment of myasthenia gravis and other diseases (22). In addition, it was introduced in the 1980s for the pharmacological pretreatment of nerve agent poisonings (23). Pyridostigmine is rapidly absorbed following oral administration determined as inhibition of the blood cholinesterases. The maximum inhibition is achieved 2-3 hrs and lasts more than $8 \mathrm{hrs}$. The half-life of inhibition is about $20 \mathrm{hrs}(21,24,25)$. The main reason for the widespread adoption of pyridostigmine as a prophylactic antidote against nerve agents is the fact that it does not influence the ability of the troops to perform the combat mission probably due to its inability to inhibit AChE in the central nervous system. Nevertheless, our results demonstrate the shortage of effectiveness of pyridostigmine bromide alone to increase the resistance of nerve agent-exposed experimental animals (13). Pyridostigmine is positively charged and, therefore, it does not readily cross $\mathrm{BBB}$ to afford the protection of brain AChE. In addition, a recent review emphasizes that this type of classic pharmacological pretreatment can produce behavioral impairment and region-specific alterations in ACh receptors at the doses required to afford protection against convulsant doses of nerve agents (26-27).

Therefore, the searching for less toxic, more effective and centrally active reversible inhibitors of AChE seems to be rationale to increase the effectiveness of pharmacological pretreatment of nerve agent poisonings. The administration of reversible inhibitors of AChE, that are able to cross BBB, should bring the protection of brain AChE from irreversible inhibition by nerve agents. This fact is important and useful for the increase of resistance of organism against nerve agents and the increase of the efficacy of post-exposure antidotal treatment. Of course, it is necessary to be careful with the dosage of centrally acting prophylactic drug. The doses of reversible inhibitors of AChE must be sufficiently safe to avoid peripheral as well as central adverse drug reactions and to maintain battle readiness of troops. Physostigmine is one of the most important representative of central inhibition of AChE (21). However, it produces marked behavioral impairment at doses sufficient to contribute to protection against a convulsant dose of soman (27). Recently, some alternative substances with known anti-cholinesterase activity have been studied to evaluate their prophylactic efficacy in comparison with pyridostigmine bromide (28-31). Some of them are already in clinical use or have been developed as potential therapeutics for other indications such as myasthenia gravis (32) or Alzheimer's disease (AD) (33-34). Among them, some substituted analogues of tacrine, a reversible inhibitor of AChE that was launched in 1993 as the first drug for the symptomatic treatment of $A D$ (35), seem to be promising, sufficiently effective reversible inhibitors of AChE, suitable for the pharmacological pretreatment of nerve agent poisonings. Especially, tacrine derivatives substituted in the position 6 of the tetrahydroacridine moiety (such as 6-chlorotacrine) were found to be very promising reversible inhibitors od AChE because they exerted relative steric freedom and favorable electron-attracting effect that represents a possibility of a hydrophobic interaction between some amino acid residues and substituents in position 6 of tacrine in the active site of AChE (36). The IC value of 6-chlorotacrine was calculated for human AChE and corresponds to $0.2 \pm 0.001 \mu \mathrm{M}$. It means that 6-chlorotacrine is very strong inhibitor of AChE (37). It is able to increase the resistance of experimental animals against 
lethal toxicity of soman and to increase the therapeutic efficacy of standard antidotal treatment of acute soman poisoning. It was found to be more effective and less toxic than commonly used pyridostigmine bromide (15).

The effect of reversible inhibitors of AChE administered prior nerve agent exposure strongly depends on their ability to protect enough peripheral and central AChE from irreversible inhibition by nerve agents. Therefore, it is important to find the optimal dose of each reversible inhibitor of AChE (including 6-chlorotacrine) to reach the maximal prophylactic efficacy. The optimal dose should as effective as possible but, at the same time, sufficiently safe. Our results clearly demonstrated the influence of the dose of 6-chlorotacrine on its ability to increase the resistance of experimental animals against acute toxicity of soman and to increase the efficacy of post-exposure antidotal treatment. When 6-chlorotacrine was administered at the maximal therapeutic dose corresponding to $20 \%$ of its $\mathrm{LD}_{50}$, its prophylactic efficacy was markedly higher than the efficacy of its lower doses corresponding to 5 or $10 \%$ of its $\mathrm{LD}_{50}$. Generally, the tacrine analogues exert the prophylactic efficacy due to their potency to reversibly inhibit AChE in the peripheral and central nervous systems but they must be administered at sufficiently effective and sufficiently safe dose. As the acute toxicity of effective tacrine analogues studied is usually lower compared to commonly used pyridostigmine, their safe optimal dose is higher and more effective.

\section{CONCLUSION}

Our results show that centrally acting reversible inhibitors of AChE are still promising drugs for pharmacological pretreatment of nerve agent exposure, significantly more effective than commonly used pyridostigmine bromide when they are administered at optimal doses. Nevertheless, the basic principle of pharmacological preatreatment of nerve agent poisonigs - the protection of AChE from nerve agent-induced irreversible inhibition by administration of reversible AChE inhibitors is somewhat limited, especially by relatively high toxicity of sufficiently effective reversible inhibitors of AChE and by the risk of potential behavioral impairment at doses required to afford sufficient protection against convulsive doses of nerve agents.

\section{ACKNOWLEDGEMENTS}

The authors express their appreciation to Mrs J. Uhlirova for her skill technical assistance. The study was funded by the grant of Ministry of Defense of the Czech Republic - "Long-term organization development plan Medical Aspects of Weapons of Mass Destruction of the Faculty of Military Health Sciences, University of Defence".

\section{REFERENCES}

1. Bajgar J. Organophosphate/nerve agent poisoning: mechanism of action, diagnosis, prophylaxis and treatment. Adv Clin Chem 2004; 38 : 151-216.
2. Colovic MB, Krstic DZ, Lazarevic-Pasti TD, Bondzic AM, Vasic VM. Acetylcholinesterase Inhibitors: Pharmacology and Toxicology. Curr Neuropharmacol 2013; 11:315-335.

3. Jokanovic M, Prostran, M. Pyridinium oximes as cholinesterase reactivators. Structure-activity relationship and efficacy in the treatment of poisoning with organophosphorus compounds. Curr Med Chem 2009; 16: 2177-2188.

4. Kassa, J. Review of oximes in the antidotal treatment of poisoning by organophosphorus nerve agents. J Toxicol Clin Toxicol 2002; 40: 803-816.

5. Shih TM. Comparison of several oximes on reactivation of soman-induced blood, brain and tissue cholinesterase activity in rats. Arch Toxicol 1993; 67: 637-646.

6. Lorke DE, Kalasz H, Petroianu GA, Tekes K. Entry of oximes into the brain: A review. Curr Med Chem 2008; 15: 743-753.

7. Zdarova Karasova J, Zemek F, Bajgar J, et al. Partition of bispyridinium oximes (trimedoxime, K074) administered in therapeutic doses into different parts of the rat brain. J Pharm Biomed Anal 2011; 54: 1082-1087.

8. Bajgar J, Fusek J, Kassa J, Kuca K, Jun D. Chemical aspects of pharmacological prophylaxis against nerve agent poisoning. Curr Med Chem 2009; 16: 2977-2986.

9. Layish I, Krivoy A, Rotman E, Finkelstein A, Tashma Z, Yehezkelli Y. Pharmacologic prophylaxis against nerve agent poisoning. Isr Med Assoc J 2005; 7: 182-187.

10. Patocka J, Jun D, Bajgar J, Kuca K. Prophylaxis against nerve agent intoxication. Def Sci J 2006; 56: 775-784.

11. Wenger B, Quigley MD, Kokla MA. Seven-day pyridostigmine administration and thermoregulation during rest and exercise in dry heat. Aviat Space Environ Med 1993; 64: 905-911.

12. Marrs TC. Organophosphate poisoning. Pharmacol Therap 1993; 58 : 51-66.

13. Kassa J, Vachek J. A comparison of the efficacy of pyridostigmine alone and the combination of pyridostigmine with anticholinergic drugs as pharmacological pretreatment of tabun-poisoned rats and mice. Toxicology 2002; 177: 179-185.

14. Kassa J, Koupilova M., Herink J, Vachek J. The long term influence of low-level sarin exposure on behavioral and neurophysiological functions in rat. Acta Medica (Hradec Králové) 2001; 44: 21-27.

15. Kassa J, Korabecny J, Nepovimova E. The evalution of benefit of newly prepared reversible inhibitors of acetylcholinesterase and commonly used pyridostigmine as pharmacological pretreatment of soman-poisoned mice. Acta Medica (Hradec Králové) 2017; 60: 37-43.

16. Tallarida R, Murray R. Manual of Pharmacological Calculation with Computer Programs. New York: Springer-Verlag, 1987.

17. Mercey G, Verdelet T, Renou J, et al. Reactivators of acetylcholinesterase inhibited by organophosphorus nerve agents. Acc Chem Res 2012; 45: 756-766.

18. Antonijevic B, Stojiljkovic MP. Unequal efficacy of pyridinium oximes in acute organophosphate poisoning. Clin Med Res 2007; 5: 71-82.

19. Marrs TC, Rice P, Vale JA. The role of oximes in the treatment of nerve agent poisoning in civilian casualties. Toxicol Rev 2006; 25: 297-323.

20. Lorke DE, Hasan MY, Nurulain SM, Shafiullah M, Kuca K, Petroianu GA. Acetylcholinesterase inhibitors as pretreatment before acute exposure to organophosphates: assessment using methyl-paraoxon. CNS Neurol Dis Drug Targets 2012; 11: 1052-1060.

21. Tuovinen K, Kaliste-Korhonen E, Raushel FM, Hanninen O. Success of pyridostigmine, physostigmine, eptastigmine and phosphotriesterase treatments in acute sarin intoxication. Toxicology 1999; 134: 169-178.

22. Komloova M, Musilek K, Dolezal M, Gunn-Moore F, Kuca K. Structure-activity relationship of quaternary acetylcholinesterase inhibitors - outlook for early myasthenia gravis treatment. Curr Med Chem 2010; 17: 1810-1824.

23. Keeler JR, Hurst CG, Dunn MA. Pyridostigmine used as a nerve agent pretreatment under wartime condition. JAMA 1991; 266: 693-695.

24. Gordon RK, Haigh JR, Garcia GE, Feaster SR, Riel MA, Lenz DE. Oral administration of pyridostigmine bromide and huperzine A protects human whole blood cholinesterases from ex vivo exposure to soman. Chem-Biol Interact 2005; 157: 239-246.

25. Fusek J, Bajgar J, Merka V. Prophylaxe von Vergiftungen mit Nervenkampfstoffen (Ergebnisse einer klinischen Studie). Koord Sanitatsdienst 2006; 24: 48-53.

26. Abou-Donia MB, Goldstein LB, Jones KH, et al. Locomotor and sensorimotor performance deficit in rats following exposure to pyridostigmine bromide, DEET, and permethrin, alone and in combination. Toxicol Sci 2001; 60: 305-314.

27. Myhrer T, Aas P. Pretreatment and prophylaxis against nerve agent poisoning: Are undesirable behavioral side effects unavoidable? Neurosci Biobehav Rev 2016; 71: 657-670. 
28. Kassa J, Musilek K, Koomlova M., Bajgar J. A comparison of the efficacy of newly developed reversible inhibitors of acetylcholinesterase with commonly used pyridostigmine as pharmacological pre-treatment of soman-poisoned mice. Bas Clin Pharmacol Toxicol 2012; 110: 322-326.

29. Lorke DE, Hasan MY, Nurulain SM, Shafiullah M, Kuca K, Petroianu GA. Pretreatment for acute exposure to diisopropylfluorophosphate: in vivo efficacy of various acetylcholinesterase inhibitors. J Appl Toxicol 2011; 31: 515-523.

30. Petroianu GA, Hasan MY, Nurulain SM, Arafat K, Sheen R, Nagelkerke N. Comparison of two pre-exposure treatment regimens in acute organophosphate (paraoxon) poisoning in rats: tiapride vs pyridostigmine. Toxicol Appl Pharmacol 2007; 219: 235-240.

31. Petroianu GA, Nurulain SM, Shafiullah M, Hasan MY, Kuca K, Lorke DE. Usefulness of administration of non-organophosphate cholinesterase inhibitors before acute exposure to organophosphates: assessment using paraoxon. J Appl Toxicol 2013; 33: 894-900.

32. Komloova M, Musilek K, Horova A, et al. Preparation, in vitro screening and molecular modelling of symmetrical bis-quinolinium cho- linesterase inhibitors-implications for early Myasthenia gravis treatment. Bioorg Med Chem Lett 2011; 21: 505-509.

33. Korabecny J, Musilek O, Holas O, et al. Synthesis and in vitro evaluation of N-(bromobut-3-en-7-yl)-7-methoxy-1,2,3,4-tetrahydroacridine-9-amine as a cholinesterase inhibitor with regard to Alzheimer's disease treatment. Molecules 2010; 15: 8804-12.

34. Spilovska K, Korabecny J, Kral J, et al. 7-methoxy-tacrine-adamantylamine heterodimers as cholinesterase inhibitors in Alzheimer's disease treatment - synthesis, biological evaluation and molecular modeling studies. Molecules 2013; 18: 2397-2418.

35. Davis KL, Powchik P. Tacrine. Lancet 1995; 345: 625-630.

36. Recanatini M, Cavalli A, Belluti F, et al. SAR of 9-amino-1,2,3,4-tetrahydroacridine-based acetycholinesterase inhibitors: synthesis, enzyme inhibitory activity, QSAR and structure-based CoMFA of tacrine analogues. J Med Chem 2000; 43: 2007-2018.

37. Nepovimova E, Korabecny J, Dolezal R, et al. Tacrine-trolox hybrids: A novel class of centrally active, nonhepatotoxic multi-target-directed ligands exerting anticholinesterase and antioxidant activities with low in vivo toxicity. J Med Chem 2015; 58: 8985-9003. 